\title{
Predicting factors of outcome in multidisciplinary treatment of chronic neuropathic pain
}

\author{
Maryam Shaygan' \\ Andreas Böger ${ }^{2}$ \\ Birgit Kröner-Herwig ${ }^{3}$ \\ 'Department of Psychiatric Nursing, \\ Community Based Psychiatric Care \\ Research Centre, Faculty of Nursing \\ and Midwifery, Shiraz University \\ of Medical Sciences, Shiraz, Iran; \\ 2Pain Management Clinic at the Red \\ Cross Hospital, Kassel, Germany; \\ ${ }^{3}$ Department of Clinical Psychology \\ and Psychotherapy, Georg-Elias- \\ Müller-Institute of Psychology, \\ Georg-August-University, Göttingen, \\ Germany
}

This article was published in the following Dove Press journal: Journal of Pain Research

\begin{abstract}
Purpose: Evidence of the effectiveness of multidisciplinary treatment with a focus on neuropathic pain is still rare. The present study investigated whether multidisciplinary treatment leads to improvement of neuropathic pain in outcome (pain intensity and disability) and psychological (depression, pain acceptance, and catastrophizing) variables at posttreatment and 3-month follow-up. We examined whether and to what extent psychological changes can predict long-term outcome at 3-month follow-up, when other variables are controlled for (baseline characteristics and changes in pain parameters).
\end{abstract}

Patients and methods: Patients suffering from a chronic neuropathic pain condition ( $n=141)$ attended an inpatient multidisciplinary program lasting about 15 continuous days with self-report data collected at pretreatment, posttreatment, and 3-month follow-up.

Results: Repeated-measures ANOVAs showed a significant improvement of pain intensity, disability, pain acceptance, catastrophizing, and depression at posttreatment. These improvements remained stable over the 3-month follow-up for all variables except for depression. The inclusion of psychological changes in multiple regression analyses greatly increased the variance in outcome, explained by baseline characteristics and changes in pain parameters.

Conclusion: The results could help clinicians to determine which variables should be emphasized during inpatient treatment and during the follow-up period, in order to maintain the gains after an inpatient multidisciplinary treatment for neuropathic pain.

Perspective: The present study demonstrates the beneficial effects of an inpatient multidisciplinary program for neuropathic pain and further question the resistant nature of neuropathic pain to treatment. The results add evidence to the relevance of cognitive-behavioral models of pain positing an important role for pain-related thoughts and emotions in long-term outcome following multidisciplinary pain treatment.

Keywords: multidisciplinary treatment, neuropathic pain, psychological variables

\section{Introduction}

An increasing number of studies of chronic pain have found that the neuropathic pain is denoted by a high level of intensity, negative affectivity, as well as disability. ${ }^{1-6}$ Neuropathic pain is a challenge to pain management as it is frequently refractory to treatment. ${ }^{7-9}$ Several studies have shown that multidisciplinary treatment can be beneficial for chronic pain. ${ }^{10-13}$ However, evidence of the effectiveness of multidisciplinary treatment with a focus on neuropathic pain syndromes is still rare. ${ }^{7,8}$ Multidisciplinary interventions for pain have gained more and more acceptance, as it has become evident that pain and disability are not only influenced by somatic pathology, but also by social and psychological factors, such as depression and pain catastrophizing, both
Correspondence: Maryam Shayga Faculty of Nursing and Midwifery, Shiraz University of Medical Sciences, P.O. Box 713451359, Shiraz, Iran

Email m2620.shaygan@gmail.com 
characterizing negative emotional processing of stressing experiences. ${ }^{14}$ Another psychological concept in explanation of the subjective processing of pain has attracted much interest in recent years, that is, the acceptance of pain, which is defined as the acknowledgment that one can be in pain and at the same time be capable of making efforts to live a satisfying life. ${ }^{15}$ Pain acceptance plays an important role in the adaptation of a patient to pain and its associated problems. ${ }^{15,16}$

There are large interindividual differences in outcomes of multidisciplinary treatment of pain. ${ }^{17,18}$ It is quite probable that the outcome of treatment is influenced by specific characteristics of patients such as sociodemographic characteristics, ${ }^{12,19,20}$ levels of pain, and disability ${ }^{12,21}$ at the onset of treatment. Additionally, several psychological characteristics such as depression, pain catastrophizing, and acceptance ${ }^{12,22,23}$ may contribute to a better or worse outcome of pain treatment. So far, findings in this area are inconclusive and often contradictory. For instance, de Rooij et al $^{12}$ reported that a better outcome of multidisciplinary treatment in chronic widespread pain is predicted by male gender, less pain, and anxiety at baseline. In contrast, further studies have reported better treatment outcomes for females and patients with more pain, disability, and depression at baseline. ${ }^{19,20}$ Some studies have not found any predictive value of sex and depression. ${ }^{24}$ Recent studies showed catastrophizing ${ }^{25,26}$ and pain acceptance ${ }^{18,27}$ to be the strongest predictors of pain treatment in various types of chronic pain (eg, low-back pain, musculoskeletal pain, and fibromyalgia). Little attention has been given to neuropathic pain, in spite of the fact that neuropathic pain is assumed to be mostly very unpleasant and more persistent than other types of pain. ${ }^{5,28} \mathrm{It}$, therefore, might respond differently to therapy as well. ${ }^{29}$

The present study investigated two main issues of research. First, it related to the question of whether multidisciplinary treatment leads to improvement of neuropathic pain in the most significant outcome variables pain intensity and disability, at the discharge period of an inpatient therapy and further, at a 3-month follow-up. A further question addressed a possible parallel change in the psychological variables depression, pain acceptance, and catastrophizing. The authors expected significant changes in both sets of variables at the two assessment periods. Second, we were interested in whether the expected psychological changes at posttreatment and follow-up would predict long-term treatment outcome in pain and disability at follow-up. We wanted to find out to what extent psychological changes can predict long-term outcome when other variables are controlled for (baseline characteristics and changes in pain parameters).
Potential predictors studied were baseline characteristics of the patients, including sociodemographic variables like age and sex, pain-associated variables like history, chronicity of pain, as well as psychological variables such as depression, pain acceptance, and catastrophizing. Furthermore, changes in psychological variables from pretreatment to posttreatment and to follow-up were investigated as possible predictors of long-term outcome. According to cognitive-behavioral models of pain, pain treatment programs are effective if they alter pain-related cognitions and coping responses. If this is true, long-term treatment outcome in pain and disability at follow-up would be associated to changes in psychological variables. Identifying psychological changes at posttreatment and follow-up associated with a better outcome at follow-up may help physicians to decide whether and when the initial inpatient treatment should cease and alternative methods of treatment should be tested.

\section{Methods}

\section{Participants}

Participants were 141 consecutive patients suffering from a chronic neuropathic pain condition who were admitted to an inpatient, multidisciplinary program at the Red Cross Hospital, Kassel, Germany. Patients were included in the program if they met the following criteria:

- patients aged $\geq 18$ years,

- patients diagnosed with probable or definite chronic neuropathic pain according to revised grading criteria for neuropathic pain, ${ }^{30}$ which was assessed by pain specialists.

Patients with one of the following neurologic syndromes were included into the study:

- post-herpetic neuralgia defined as herpes zoster-related pain persisting or appearing more than 3 months after the acute herpes zoster $\operatorname{rash}^{31,32}(n=13)$,

- complex regional pain syndrome type II according to clinical criteria ${ }^{33}(n=17)$,

- central neuropathic pain defined as pain caused by a demonstrable lesion in the central nervous system in an area anatomically attributable to the $\operatorname{lesion}^{7}(n=9)$,

- polyneuropathy according to clinical criteria ${ }^{34}(n=35)$,

- trigeminal neuralgia according to diagnostic grading system for trigeminal neuralgia ${ }^{35}(n=8)$,

- chronic neuropathic low-back pain (radiculopathy) with a history of nerve root damage and typical dermatomal pain (radiating beyond the knee, pain evoked by stretching 
of the femoral nerve, clinical signs of nerve root involvement, including sensory or motor deficits in the leg and decrease or loss of tendon reflexes $)^{36}(n=59)$.

The patients were excluded if they had a pain history of $<6$ months; medical or psychiatric illness interfering with the pain assessment; and an inability to comprehend the German language.

All participants gave written informed consent. The study was approved by the Ethics Committee of the Georg-EliasMueller Institute of Psychology.

\section{Pain treatment program}

Patients were enrolled in an inpatient multidisciplinary program lasting about 15 continuous days in a pain treatment center at the Red Cross Hospital, Kassel, Germany. Based on a multidisciplinary approach, every patient was assessed by every specialty participating in the program. The multidisciplinary team involved specialized pain therapists such as neurologists and physiotherapists, as well as occupational therapists, psychotherapists, and social workers. The treatment included pharmacotherapy, physical approaches (such as exercise, physiotherapy, and rehabilitation), psychological approaches including psychological counseling, cognitivebehavioral interventions, self-help strategies, and the acquisition of pain management skills. The treatment was tailored to the patients' personal goals and conditions (such as type of pain) and was performed in groups and on an individual basis. The multidisciplinary team discussed the treatment progress as well as time of discharge for each patient during regular team meetings.

Before the start of the treatment program, patients completed the baseline measurements of demographic, painrelated, and psychological variables (T0). Immediately at the end of the treatment program (T1) and 3 months later (T2), the instruments of pain-related and psychological variables were reapplied and the posttreatment and follow-up scores were obtained.

\section{Measures}

In addition to the standard sociodemographic assessment (age, sex, marital status, educational level, and work absence), the following variables were measured:

- Pain intensity was assessed with the numeric rating scale (0 [no pain] to 10 [worst imaginable pain]). Adequate psychometric properties have been reported. ${ }^{37}$

- Pain-related disability was measured by the pain disability index (PDI). ${ }^{38}$ It assesses subjective disability in seven areas: home/family responsibilities, recreation, social activities, occupation, sexual behavior, self-care, and life support activities scored on a 11-grade format ranging from " 0 " (no disability) to " 10 " (total disability). The PDI total score is calculated by summing the seven-item responses. A higher score indicates a higher level of disability. In a study by Dillmann et al, ${ }^{39}$ the reliability and validity of the German version of the instrument were confirmed. They found a significant correlation between the PDI score and the Oswestry Low Back Pain Disability Questionnaire $^{40}(r=0.76)$. A high internal consistency of the instrument (Cronbach's alpha $=0.88$ ) was reported..$^{39}$

- Frequency of pain was assessed by asking participants to indicate the frequency of pain experienced during the past week. Response options were several times in a week, several times every day, and permanent.

- Pain history was assessed by the question "How long have you been suffering from chronic pain"? Participants were asked to indicate the number of years they have experienced pain.

- Pain chronicity was assessed by the Mainz Pain Staging System (MPSS), ${ }^{41}$ which defines three stages of pain chronicity based on ten questions regarding occurrence of pain, pain duration, distribution, and so on. The MPSS has shown appropriate validity. ${ }^{42}$

- Depressive symptoms were assessed by the German short version of the Center for Epidemiological Studies Depression Scale. ${ }^{43}$ The scale consists of 15 items (4-point Likert scale; $0=$ rarely, $3=$ most of the time $)$. The questionnaire has been shown to be a reliable (Cronbach's alpha $=0.91$ ) and valid measure of depressive symptoms. ${ }^{44}$

- Catastrophizing was assessed with the German version of the Pain Catastrophizing Scale (PCS, subscale "helplessness"). ${ }^{45}$ The subscale "helplessness" describes the feeling of the inability to cope with the pain. It includes six items (5-point Likert scale; $0=$ not at all, $4=$ all the time). According to Sullivan et al, ${ }^{46}$ a total score of 13 represents clinically relevant levels of "helplessness". The PCS-helplessness subscale has shown the most appropriate construct validity compared to the other subscales of the PCS. ${ }^{45,46}$ This subscale has strong internal consistency (Cronbach's alpha $=0.89$ ) in the present sample.

- Pain acceptance was measured by ten items from the German version of the Chronic Pain Acceptance Questionnaire (items 1, 2, 6, 9, 12, and 15 for Activity engagement and items 13, 14, 11, and 18 for Pain willingness). ${ }^{47}$ These items have shown the highest correlation with the total score of the questionnaire. ${ }^{47}$ Items were scored on 
a 7 -grade format $(0=$ never, $6=$ always $) .{ }^{47}$ Higher scores indicate higher levels of acceptance. The selected items demonstrate an excellent internal consistency in the present study (Cronbach's alpha $=0.91$ ). The total score of items showed moderate-to-high correlations with measures of disability $(r=-0.53)$, depression $(r=-0.56)$, and catastrophizing $(r=-0.53)$, thus demonstrating convergent validity.

\section{Statistical analysis}

Descriptive statistics, such as means and SDs for continuous variables and frequencies and percentages for categorical variables, were used for all demographic variables and pretreatment measures.

Repeated-measures ANOVA and post hoc Bonferroni tests were performed to identify changes in the outcome and psychological variables from pretreatment (T0) to posttreatment (T1) and to follow-up (T2).

Univariate and multiple regression analyses were used to evaluate the predictors of treatment outcomes. The changes in pain intensity and disability from pretreatment to follow-up (T0-T2) were entered as the dependent variables.

First, explorative univariate regression analyses assessed the association of every potential predictor individually with each of the outcome variables. After conducting univariate analyses, variables with a statistical significance of 0.20 and below were entered into hierarchical multiple regression analyses (method: Enter). In multiple regression analyses, first, baseline characteristics of patients were assessed regarding their association with outcome. In a second step, change in outcome variables at posttreatment was entered into the model. Finally, changes in psychological variables were fed into the model. We wanted to determine whether the inclusion of psychological changes increased the explained variance in the outcomes after controlling for the previously entered variables. This statistical strategy allows the determination of the increase in explained variance by each block of variables entered. Variance inflation factors were calculated for the independent variables in order to test the assumption of collinearity. ${ }^{48}$ The SPSS Software, version 21 was applied. The significance level was set at $P<0.05$.

\section{Results}

\section{Study sample}

Of the total 159 patients with a chronic neuropathic pain condition, 141 patients met the study criteria. A total of 18 patients had to be excluded from the study: two patients who refused to participate, nine patients because of insufficient follow-up data for further evaluation, four patients had pain of less than 6 months duration, two patients had a medical illness interfering with the pain assessment (eg, Alzheimer's disease), and one patient due to rehospitalization related to pain during the follow-up period.

The mean age of the participating patients was 60.13 years ( $S D=12.68$ ), and the majority of patients were women (64\%). Most patients were married (61\%) and $\sim 45 \%$ of patients had primary education (Table 1 ). Average pain intensity over the past week before enrolment to the program was $6.8(\mathrm{SD}=1.7)$ (Table 1). The average pain history was 7.64 years $(\mathrm{SD}=8.2)$ and $\sim 93 \%$ of patients had a pain history of more than 1 year. The average length of the inpatient multidisciplinary program for patients was 14.92 days $(\mathrm{SD}=4.28$; Table 1$)$.

\section{Outcome}

One-way repeated-measures ANOVAs revealed that there were significant main effects of time on ratings of

Table I Sample characteristics $(n=|4|)$

\begin{tabular}{|l|l|}
\hline Characteristic & Value \\
\hline Age (M \pm SD) & $60.1 \pm I 2.6$ \\
Sex, $\mathrm{n}(\%)$ & \\
Female & $90(64 \%)$ \\
Marital status & \\
Married & $85(61 \%)$ \\
Single & $12(8.6 \%)$ \\
Divorced/separated & $17(12.2 \%)$ \\
Living with a partner & $9(6.5 \%)$ \\
Widowed & $16(11.5 \%)$ \\
Educational level & \\
None & $4(2.9 \%)$ \\
Primary education & $62(45.3 \%)$ \\
Secondary education & $52(38 \%)$ \\
High school certificate & $7(5.1 \%)$ \\
College or university degree & $12(8.8 \%)$ \\
Pain history (years) & $7.64(8.2)$ \\
Frequency of pain & \\
Several times in a week & $9(6.5 \%)$ \\
Several times every day & $39(28.5 \%)$ \\
Permanent & $89(65 \%)$ \\
Work absence (days) & $11.0 \pm 13.8$ \\
Length of hospital days & $14.92 \pm 4.28$ \\
Pain intensity (NRS) & $6.8 \pm 1.7$ \\
Pain chronicity (MPSS) & $8.9 \pm 1.3$ \\
Disability (PDI) & $37.7 \pm 13.9$ \\
Depression (ADS-K) & $16.9 \pm 10.0$ \\
Pain acceptance (CPAQ) & $30.8 \pm 10.4$ \\
Pain catastrophizing (PCS-H) & $11.9 \pm 5.5$ \\
\hline
\end{tabular}

Abbreviations: ADS-K, Allgemeine Depressions Skala-Kurz version; CPAQ, Chronic Pain Acceptance Questionnaire; M, mean; MPSS, Mainz Pain Staging System; n, number; NRS, numeric rating scale; PCS-H, Pain Catastrophizing ScaleHelplessness; PDI, pain disability index. 
pain intensity $(\mathrm{F}[2 / 146]=41.6, P=0.000)$ and disability (F $[2 / 140]=26.8, P=0.000)$. In addition, the predictor variables depression $(\mathrm{F}[2 / 130]=21.3, P=0.000)$, pain acceptance $(\mathrm{F}[2 / 144]=7.5, P=0.001)$, and catastrophizing (F $[2 / 148]=14.2, P=0.000$, Table 2 ) showed a significant time effect.

The time effect indicates that multidisciplinary treatment possibly led to a significant improvement of pain condition, as shown in the reduction of intensity and disability at posttreatment and follow-up. Pairwise comparisons between pretreatment and posttreatment (T0-T1) and between pretreatment and follow-up (T0-T2) showed significant improvements in outcome variables (Table 2). Most patients (81\%) had a clinically significant change in pain intensity (two or more points on a $0-10$ numerical rating scale ${ }^{49,50}$ from pretreatment to posttreatment (T0-T1) and $\sim 49 \%$ reported a clinically meaningful change in pain intensity between pretreatment and follow-up (T0-T2).

Similarly, the psychological predictors showed significant changes over time in terms of improvement of pain acceptance and catastrophizing from pretreatment to posttreatment and to follow-up in patients with chronic neuropathic pain. Depression showed an improvement from pretreatment to posttreatment but not to follow-up (Table 2).

\section{Univariate regression models}

\section{Outcome variable pain intensity}

Univariate regression models revealed that sex, baseline pain intensity, and change in pain intensity after treatment period (T0-T1) were significantly associated with the change in pain intensity after the 3-month follow-up (T0-T2). Change in disability from pretreatment to follow-up was also a significant predictor of the follow-up effect in pain intensity. The psychological predictor variables depression, pain acceptance, and catastrophizing at baseline and after treatment period had no influence on outcome in pain intensity at follow-up. However, changes in the psychological variables from pretreatment to the follow-up predicted the follow-up outcome in pain intensity (Table 3 ).

\section{Outcome variable disability}

Treatment outcome regarding disability (T0-T2) was significantly correlated with pain history and baseline disability. Posttreatment outcome in intensity and disability was associated with follow-up results in disability. Change in pain intensity from pretreatment to follow-up was also a significant predictor of the follow-up effect in disability. As with pain intensity, there was no prediction of outcome by the psychological variables at baseline and posttreatment. However, the follow-up outcome in disability was strongly influenced by changes in all psychological variables at followup, as was seen in pain intensity (Table 3 ).

\section{Multiple regression analyses Outcome variable pain intensity}

In the first step of the hierarchical regression analyses, sex, pain history, baseline pain intensity, chronicity, and acceptance were assessed regarding their association with change in pain intensity (T0-T2). Pain intensity at baseline turned out to be a significant predictor in this model $(P=0.003)$, but other baseline variables did not. This model achieved a variance explanation of $24 \%$. In the second step, change in pain intensity after treatment period (T0-T1) was included in the model. This variable made significant contribution to the explanation of variance in "change in pain intensity", but the variable "pain intensity at baseline" did not maintain its status as a predictive variable $(P=0.14)$. This model achieved a variance explanation of $11 \%$ more than the previous model

Table 2 Repeated-measures ANOVAs, mean \pm SDs, F-ratios, $P$-values, partial $\eta^{2}$, and Bonferroni post hoc tests

\begin{tabular}{|c|c|c|c|c|c|c|c|c|}
\hline \multirow[t]{2}{*}{ Variables } & \multirow[t]{2}{*}{$\begin{array}{l}\text { Pretreatment } \\
\text { (T0) }\end{array}$} & \multirow[t]{2}{*}{$\begin{array}{l}\text { Posttreatment } \\
\text { (TI) }\end{array}$} & \multirow{2}{*}{$\begin{array}{l}\text { 3-month } \\
\text { follow-up } \\
\text { (T2) }\end{array}$} & \multirow[t]{2}{*}{$F(d f)$} & \multirow[t]{2}{*}{$P$} & \multirow[t]{2}{*}{$\eta^{2}$} & \multicolumn{2}{|c|}{$\begin{array}{l}\text { Bonferroni tests } \\
\text { Mean difference }\end{array}$} \\
\hline & & & & & & & T0-TI & T0-T2 \\
\hline Pain intensity & $6.8 \pm 1.7$ & $4.8 \pm 1.7$ & $5.5 \pm 2.1$ & $41.6(2 / 146)$ & 0.000 & 0.36 & $2.0 * * *$ & $1.3 * * *$ \\
\hline Disability & $37.4 \pm 14.5$ & $26.7 \pm 14.1$ & $30.7 \pm 15.9$ & $26.8(2 / 140)$ & 0.000 & 0.27 & 10.6 *** & $6.6 * * *$ \\
\hline Depression & $16 \pm 10.2$ & $9.5 \pm 6.5$ & $14.6 \pm 9.5$ & $21.3(2 / 130)$ & 0.000 & 0.25 & $6.4 * * *$ & $1.3^{\mathrm{ns}}$ \\
\hline Pain acceptance & $32.8 \pm 11.0$ & $36.0 \pm 10.0$ & $35.6 \pm 11.7$ & $7.5(2 / 144)$ & 0.001 & 0.09 & $-3.2 * * *$ & $-2.8 * *$ \\
\hline Pain catastrophizing & $12 \pm 5.6$ & $8.9 \pm 4.8$ & $10.3 \pm 5.8$ & $14.2(2 / 148)$ & 0.000 & 0.16 & $3.1^{* * *}$ & $1.7^{*}$ \\
\hline
\end{tabular}

Notes: ${ }^{* * *} P<0.001 ;{ }^{* * P}<0.01$; $* P<0.05$; ${ }^{\text {ns }}$ Not significant.

Abbreviation: $\mathrm{df}$, degrees of freedom. 
Table 3 Results of univariate regression analyses of change in pain and disability

\begin{tabular}{|c|c|c|c|c|c|c|}
\hline \multirow{2}{*}{$\begin{array}{ll}\text { Predictors } & \\
\end{array}$} & \multicolumn{3}{|c|}{ Change in pain intensity (T0-T2) } & \multicolumn{3}{|c|}{ Change in disability (T0-T2) } \\
\hline & B & $\beta$ & $P$ & B & $\beta$ & $P$ \\
\hline \multicolumn{7}{|l|}{ Baseline characteristics } \\
\hline \multicolumn{7}{|l|}{ Demographic variables } \\
\hline Age & 0.008 & 0.04 & 0.66 & -0.11 & -0.11 & 0.31 \\
\hline Sex & 1.00 & 0.46 & $0.03^{*}$ & 5.98 & 0.21 & 0.05 \\
\hline Marital status & -0.19 & -0.09 & 0.37 & -2.16 & -0.16 & 0.11 \\
\hline Educational level & -0.01 & -0.008 & 0.94 & -1.57 & -0.11 & 0.31 \\
\hline \multicolumn{7}{|l|}{ Pain-related variables } \\
\hline Pain history (years) & -0.05 & -0.20 & 0.07 & -0.46 & -0.27 & $0.02 *$ \\
\hline Work absence (days) & -0.07 & -0.37 & 0.24 & -0.28 & -0.27 & 0.28 \\
\hline Frequency of pain & 0.18 & 0.04 & 0.66 & 4.05 & 0.16 & 0.12 \\
\hline Pain intensity & 0.47 & 0.39 & $0.000^{\text {w*ta }}$ & 0.78 & 0.10 & 0.34 \\
\hline Pain chronicity & -0.28 & -0.17 & 0.11 & -0.24 & -0.02 & 0.83 \\
\hline Disability & -0.01 & -0.06 & 0.53 & 0.29 & 0.29 & 0.006 ** \\
\hline \multicolumn{7}{|l|}{ Psychological variables } \\
\hline Depression & -0.02 & -0.12 & 0.26 & 0.05 & 0.03 & 0.72 \\
\hline Pain acceptance & 0.03 & 0.16 & 0.12 & 0.02 & 0.02 & 0.83 \\
\hline Pain catastrophizing & -0.006 & -0.01 & 0.88 & 0.32 & 0.12 & 0.24 \\
\hline \multicolumn{7}{|l|}{ Posttreatment changes } \\
\hline \multicolumn{7}{|l|}{ Pain-related variables } \\
\hline Change in pain intensity (T0-TI) & 0.65 & 0.59 & $0.000^{* * * *}$ & 1.65 & 0.24 & $0.03 *$ \\
\hline Change in disability (T0-TI) & 0.007 & 0.03 & 0.74 & 0.49 & 0.44 & $0.000^{* \text { kpk }}$ \\
\hline \multicolumn{7}{|l|}{ Psychological variables } \\
\hline Change in pain acceptance (T0-TI) & -0.006 & -0.01 & 0.87 & -0.20 & -0.11 & 0.34 \\
\hline Change in pain catastrophizing (T0-TI) & 0.04 & 0.11 & 0.32 & 0.36 & 0.14 & 0.24 \\
\hline Change in depression (T0-TI) & -0.01 & -0.07 & 0.52 & 0.20 & 0.26 & 0.03 \\
\hline \multicolumn{7}{|l|}{ Follow-up changes } \\
\hline \multicolumn{7}{|l|}{ Pain-related variables } \\
\hline Change in pain intensity (T0-T2) & - & - & - & 2.61 & 0.47 & $0.000^{\text {kok }}$ \\
\hline Change in disability (T0-T2) & 0.08 & 0.47 & $0.000^{* * * *}$ & - & - & - \\
\hline \multicolumn{7}{|l|}{ Psychological variables } \\
\hline Change in pain acceptance (T0-T2) & -0.10 & -0.43 & $0.000^{\text {*** }}$ & -0.79 & -0.59 & $0.000^{* \text { *at }}$ \\
\hline Change in pain catastrophizing (T0-T2) & 0.17 & $0.4 \mathrm{I}$ & $0.000^{* * * *}$ & 1.30 & 0.54 & $0.000^{* \text { kpk }}$ \\
\hline Change in depression (T0-T2) & 0.11 & 0.40 & $0.000^{\text {watk }}$ & 0.79 & 0.51 & $0.000^{* \text { *ate }}$ \\
\hline
\end{tabular}

Notes: ${ }^{* * * P<0.001 ; * * P<0.01 ; * P<0.05}$.

$\left(R^{2}=35 \%\right)$. Finally, changes in psychological variables were entered into the model. Changes in pain acceptance $(P=0.01)$ and catastrophizing $(P=0.01)$ from pretreatment to the followup contributed to the prediction of change in pain intensity in this model. The inclusion of changes in psychological variables led to a $25 \%$ increase in explained variance, for a total explanation of variance of $61 \%$ (Table 4$)$. Baseline pain acceptance $(P=0.002)$ also made a significant contribution to the explanation of outcome in this model (Table 4).

\section{Outcome variable disability}

In the first step, sex, marital status, pain history, pain frequency, and baseline disability were assessed regarding their association with change in disability (T0-T2). Pain history $(P=0.03)$ and baseline disability $(P=0.01)$ were significantly associated with change in disability in this model, but other baseline variables were not. This model achieved a variance explanation of $28 \%$. In the second step, posttreatment changes in pain intensity and disability were included in the model. None of the variables were significantly associated with change in disability in this model. This model achieved a variance explanation of $5 \%$ more than the previous model $\left(R^{2}=33 \%\right)$. Finally, changes in psychological variables were entered into the model. The changes in depression at posttreatment $(P=0.004)$ and follow-up $(P=0.01)$ were associated with the long-term outcome in disability. Change in pain acceptance $(P=0.007)$ and catastrophizing $(P=0.02)$ from pretreatment to the follow-up also made significant contributions to the prediction of outcome in disability. The inclusion of changes in psychological variables led to a $41 \%$ increase 
Table 4 Change in pain intensity from pretreatment to 3-month follow-up: hierarchical regression analyses

\begin{tabular}{|c|c|c|c|c|c|c|}
\hline Regression model & \multirow[t]{2}{*}{ Predictors } & \multirow[t]{2}{*}{$R^{2}$} & \multirow[t]{2}{*}{ B } & \multirow[t]{2}{*}{ SEB } & \multirow[t]{2}{*}{$\beta$} & \multirow[t]{2}{*}{$P$} \\
\hline Criterion & & & & & & \\
\hline & Model I & 0.24 & & & & \\
\hline & Sex & & 0.48 & 0.53 & 0.11 & 0.36 \\
\hline & Pain history (years) & & -0.02 & 0.03 & -0.10 & 0.45 \\
\hline & Pain intensity & & 0.48 & 0.15 & 0.44 & $0.003^{* *}$ \\
\hline & Pain chronicity & & -0.14 & 0.23 & -0.09 & 0.54 \\
\hline & Pain acceptance & & 0.05 & 0.02 & 0.28 & 0.08 \\
\hline \multirow[t]{17}{*}{ Change in pain intensity (T0-T2) } & Model 2 & 0.35 & & & & \\
\hline & Sex & & 0.01 & 0.52 & 0.004 & 0.97 \\
\hline & Pain history (years) & & -0.03 & 0.03 & -0.11 & 0.36 \\
\hline & Pain intensity & & 0.25 & 0.16 & 0.22 & 0.14 \\
\hline & Pain chronicity & & -0.02 & 0.21 & -0.01 & 0.90 \\
\hline & Pain acceptance & & 0.04 & 0.02 & 0.23 & 0.12 \\
\hline & Change in pain intensity (T0-TI) & & 0.49 & 0.17 & 0.41 & $0.008^{* *}$ \\
\hline & Model 3 & 0.61 & & & & \\
\hline & Sex & & -0.04 & 0.43 & -0.10 & 0.31 \\
\hline & Pain history (years) & & -0.003 & 0.02 & -0.01 & 0.90 \\
\hline & Pain intensity & & 0.24 & 0.15 & 0.22 & 0.15 \\
\hline & Pain chronicity & & -0.08 & 0.18 & -0.05 & 0.64 \\
\hline & Pain acceptance & & 0.07 & 0.02 & 0.41 & $0.002^{* *}$ \\
\hline & Change in pain intensity (T0-TI) & & 0.21 & 0.15 & 0.18 & 0.16 \\
\hline & Change in pain acceptance (T0-T2) & & 0.08 & 0.03 & 0.34 & $0.01 *$ \\
\hline & Change in pain catastrophizing (T0-T2) & & 0.12 & 0.05 & 0.31 & $0.01 *$ \\
\hline & Change in depression (T0-T2) & & 0.01 & 0.03 & 0.04 & 0.75 \\
\hline
\end{tabular}

Notes: $* * P<0.01 ; * P<0.05$.

Abbreviation: SEB, the standard error for the unstandardized beta.

in explained variance, for a total explanation of variance of $74 \%$ (Table 5).

\section{Discussion}

The present study investigated two main questions. First, we examined whether multidisciplinary treatment leads to improvement of pain intensity and disability at the discharge period of an inpatient therapy and further, at a 3-month follow-up in patients with neuropathic pain. We also examined a possible parallel change in the psychological variables depression, pain acceptance, and catastrophizing. Second, we tested whether the expected psychological changes at posttreatment and follow-up will predict long-term treatment outcome in pain and disability after controlling for baseline characteristics and changes in pain parameters.

As hypothesized, multidisciplinary treatment led to a significant improvement of pain condition, as shown in the reduction of intensity and disability at posttreatment and follow-up. The results lend support for the beneficial effects of an intensive inpatient multidisciplinary program for neuropathic pain and further question the resistant nature of neuropathic pain to treatment. Previous research has shown that there are many individuals whose neuropathic pain has been unsuccessfully treated, despite numerous attempts at pharmacologic treatment and high use of health services. ${ }^{51}$ Our findings emphasize that neuropathic pain management should include psychosocial approaches in addition to the usual interventions such as pharmacotherapy. It is because, according to biopsychosocial model, perceived pain intensity and response to pain are influenced by an interaction of physiologic, psychological (emotions and cognitions), and social factors. ${ }^{22}$ Psychosocial interventions aim to modify patients' thoughts, feelings, and responses to pain. Previous studies suggested that patients with neuropathic pain differ from those with nociceptive pain in beliefs about pain and it has been suggested that they might also respond differently to psychological interventions. ${ }^{29}$ The present study, consistent with cognitive-behavioral models of chronic pain, shows that neuropathic pain patients who received a multidisciplinary pain treatment program demonstrated significant changes in pain acceptance, catastrophizing, and depression at posttreatment. These improvements remained stable, over the 3 months following discharge, for pain acceptance and catastrophizing, but not for depression. This finding is consistent with those of Jensen et al, ${ }^{52}$ who found an increase in depression score between posttreatment and 
Table 5 Change in disability from pretreatment to 3-month follow-up: hierarchical regression analyses

\begin{tabular}{|c|c|c|c|c|c|c|}
\hline Regression model & \multirow[t]{2}{*}{ Predictors } & \multirow[t]{2}{*}{$R^{2}$} & \multirow[t]{2}{*}{ B } & \multirow[t]{2}{*}{ SEB } & \multirow[t]{2}{*}{$\beta$} & \multirow[t]{2}{*}{$P$} \\
\hline Criterion & & & & & & \\
\hline & Model I & 0.28 & & & & \\
\hline & Sex & & 6.0 & 3.2 & 0.24 & 0.07 \\
\hline & Marital status & & -1.42 & 1.52 & -0.12 & 0.35 \\
\hline & Pain history (years) & & -0.46 & 0.20 & -0.29 & $0.03 *$ \\
\hline & Frequency of pain & & -0.57 & 2.95 & -0.02 & 0.84 \\
\hline & Disability & & 0.27 & 0.10 & 0.34 & $0.01 *$ \\
\hline & Model 2 & 0.33 & & & & \\
\hline & Sex & & 3.05 & 3.68 & 0.12 & $0.4 I$ \\
\hline & Marital status & & -1.18 & 1.52 & -0.10 & 0.44 \\
\hline & Pain history (years) & & -0.35 & 0.21 & -0.23 & 0.10 \\
\hline \multirow[t]{16}{*}{ Change in disability (T0-T2) } & Frequency of pain & & 0.11 & 2.95 & 0.005 & 0.97 \\
\hline & Disability & & 0.17 & 0.12 & 0.20 & 0.19 \\
\hline & Change in pain intensity (T0-TI) & & 1.03 & 0.94 & 0.15 & 0.28 \\
\hline & Change in disability (T0-TI) & & 0.26 & 0.17 & 0.27 & 0.13 \\
\hline & Model 3 & 0.74 & & & & \\
\hline & Sex & & 3.05 & 3.68 & 0.12 & $0.4 \mathrm{I}$ \\
\hline & Marital status & & -1.18 & 1.52 & -0.10 & 0.44 \\
\hline & Pain history (years) & & -0.35 & 0.21 & -0.23 & 0.10 \\
\hline & Frequency of pain & & 0.11 & 2.95 & 0.005 & 0.97 \\
\hline & Disability & & 0.17 & 0.12 & 0.20 & 0.19 \\
\hline & Change in pain intensity (T0-TI) & & 1.03 & 0.94 & 0.15 & 0.28 \\
\hline & Change in disability (T0-TI) & & 0.26 & 0.17 & 0.27 & 0.13 \\
\hline & Change in depression (T0-TI) & & 0.48 & 0.15 & 0.35 & $0.004^{* *}$ \\
\hline & Change in pain acceptance (T0-T2) & & 0.44 & 0.15 & 0.31 & $0.007^{k+k}$ \\
\hline & Change in pain catastrophizing (T0-T2) & & 0.60 & 0.25 & 0.26 & $0.02 *$ \\
\hline & Change in depression (T0-T2) & & $0.5 \mathrm{I}$ & 0.20 & 0.35 & $0.0 I^{*}$ \\
\hline
\end{tabular}

Notes: $* * P<0.01 ; * P<0.05$.

follow-up of multidisciplinary treatment. The deterioration regarding depression might be associated with a decrease in the use of learned adaptive thought and coping strategies. Further studies are needed to determine whether maintenance interventions after the end of inpatient treatment improve long-term outcomes of depression.

As expected, psychological changes predicted the longterm treatment outcome in pain and disability at follow-up. The inclusion of psychological changes in multiple regression analyses greatly increased the total amount of variance in outcome explained by baseline characteristics and changes in pain parameters. These findings are consistent with the prediction based on cognitive-behavioral models of pain positing that patients' outcomes after treatment will be influenced by patients' thoughts and beliefs after treatment. ${ }^{53}$ The results support the relevance of the biopsychosocial approach of neuropathic pain.

Based on our results, a better outcome in pain intensity at follow-up was significantly associated with higher levels of pain acceptance at baseline. Changes in pain acceptance and catastrophizing from pretreatment to follow-up were also significant predictors of the follow-up effect in pain intensity. Similarly, follow-up outcome in disability was influenced by changes in pain acceptance and catastrophizing at follow-up. These findings are consistent with previous research. ${ }^{15,18,25,54,55}$ As noted by McCracken and Vowles, ${ }^{56}$ acceptance of one's pain and condition is one way of addressing the "beyond control" aspect of chronic pain. Research suggests that patients who accept their pain more are also more able to open up to experiences that are beyond their control, which in turn results in fewer avoidant behaviors. ${ }^{15,57}$ Increased exposure to pain may in turn lead patients to recognize that pain varies in different circumstances, and to learn that pain in reality is less severe than they thought. ${ }^{15}$ Moreover, those patients who do not attempt to control or avoid sensations of pain are patients who are least disabled by their pain. ${ }^{58}$ Consistent with this, Geiser ${ }^{54}$ found that increases in acceptance during multidisciplinary pain treatment predicted a greater improvement in disability after treatment. Together, our findings, in line with previous studies, imply that a higher level of pain acceptance at baseline and a gain in acceptance following treatment can predict a more favorable outcome after multidisciplinary pain treatment. 
The other important finding of this study was that the changes in catastrophizing from pretreatment to follow-up predict the changes in both pain intensity and disability at the same time period. These findings are consistent with those of Jensen et al, ${ }^{59}$ which also found that a decrease in catastrophizing was associated with decreases in disability and pain intensity in chronic pain patients. It has been suggested that the belief that pain will get worse and that one is helpless to deal with it (catastrophization) increases the perception of the experience of pain. In a study with functional MRI in patients with chronic pain, it was seen that characterizations of pain as awful, horrible, and unbearable are significantly associated with increased activity in brain areas related to attention to pain, emotional aspects of pain, and motor control. ${ }^{60}$ This suggests that catastrophizing plays an important role in modulating the perception of pain and responses to it. Although correlational findings do not shed light on causal relationships, current findings show that a large and statistically significant portion of the variance in changes in pain intensity and disability at follow-up can be explained by changes in cognitions at the same time period. Based on the results, changes in pain acceptance and catastrophizing at posttreatment could not predict long-term treatment outcome in pain and disability at follow-up. This may emphasize the importance of maintained gains after pain treatment and that posttreatment psychological changes may not necessarily result in long-term treatment outcomes. These findings emphasize the importance of including relapse prevention strategies in multidisciplinary pain treatment programs in order to increase the likelihood of maintained benefits after treatment.

Based on our results, long-term treatment outcomes in pain disability were also associated with posttreatment and followup changes in depression. This finding is consistent with those of Glombiewski et al, ${ }^{61}$ who found significant contributions of decreased depression to improvement in pain-related disability. The reason for this finding may be attributed to the fact that multidisciplinary treatment of pain addresses depressive symptoms, such as inactivity, through cognitive restructuring and activity scheduling. The improvement in depressive symptoms helps patients to overcome their loss of interest in daily activities, which directly result in a reduction in the disability in patients. Our findings also reveal that changes in depression after multidisciplinary pain treatment are more strongly associated with improvements in disability than pain intensity. These findings may suggest that specific psychological variables may be uniquely associated with specific pain outcomes.

It is important to mention some of the limitations of our study. First, we did not include a control group. Thus, it is not possible to definitely determine whether the changes observed in the outcome measures were the result of treatment. Nevertheless, the literature (randomized controlled trial studies) tells us that treatments such as the one performed here can have these effects. Another limitation of the study lies in the inclusion of a sample of patients from only a single clinic and thus forbids generalization. Assessing psychological variables based only on self-report questionnaires might endanger our findings. ${ }^{62}$ Furthermore, we used a shortened version of the Chronic Pain Acceptance Questionnaire with only ten items; however, these ten items showed an excellent internal consistency and convergent validity in the present sample. We could not interpret the clinical importance of individual patient improvements with regard to disability. More research with a longer follow-up and more appropriate design is needed in order to provide high-quality evidence of the effectiveness of multidisciplinary pain treatment for the management of chronic neuropathic pain.

\section{Conclusion}

In summary, our findings support cognitive-behavioral models of pain positing an important role for pain-related thoughts, emotions, and behavioral responses in long-term outcome following multidisciplinary pain treatment. The current results could help clinicians to determine which variables should be emphasized during inpatient treatment and during the follow-up period. Identification of specific cognitions and emotions linked to outcome in pain treatment could be useful to clinicians to target them during inpatient treatment and during the follow-up period, in order to maintain the gains.

\section{Acknowledgment}

The authors thank the patients for their active contribution and participation in this research.

\section{Disclosure}

The authors report no conflicts of interest in this work.

\section{References}

1. Treede RD, Jensen TS, Campbell JN, et al. Neuropathic pain: redefinition and a grading system for clinical and research purposes. Neurology. 2008;70(18):1630-1635.

2. Freynhagen R, Baron R, Gockel U, Tölle TR. painDETECT: a new screening questionnaire to identify neuropathic components in patients with back pain. Curr Med Res Opin. 2006;22(10):1911-1920.

3. Torrance N, Smith BH, Watson MC, Bennett MI. Medication and treatment use in primary care patients with chronic pain of predominantly neuropathic origin. Fam Pract. 2007;24(5):481-485.

4. Bouhassira D, Lantéri-Minet M, Attal N, Laurent B, Touboul C. Prevalence of chronic pain with neuropathic characteristics in the general population. Pain. 2008;136(3):380-387. 
5. Attal N, Lanteri-Minet M, Laurent B, Fermanian J, Bouhassira D. The specific disease burden of neuropathic pain: results of a French nationwide survey. Pain. 2011;152(12):2836-2843.

6. Shaygan M, Böger A, Kröner-Herwig B. Clinical features of chronic pain with neuropathic characteristics: a symptom-based assessment using the pain DETECT questionnaire. Eur J Pain. 2013;17(10):1529-1538.

7. Baron R, Binder A, Wasner G. Neuropathic pain: diagnosis, pathophysiological mechanisms, and treatment. Lancet Neurol. 2010;9(8):807-819.

8. Baron R, Binder A, Attal N, Casale R, Dickenson AH, Treede RD. Neuropathic low back pain in clinical practice. Eur J Pain. 2016;20(6):861-873.

9. Finnerup NB, Scholz J, Attal N, et al. Neuropathic pain needs systematic classification. Eur J Pain. 2013;17(7):953-956.

10. Kääpä EH, Frantsi K, Sarna S, Malmivaara A. Multidisciplinary group rehabilitation versus individual physiotherapy for chronic nonspecific low back pain: a randomized trial. Spine. 2006;31(4):371-376.

11. Carbonell-Baeza A, Aparicio VA, Ortega FB, et al. Does a 3-month multidisciplinary intervention improve pain, body composition and physical fitness in women with fibromyalgia? Br J Sports Med. 2011;45(15):1189-1195.

12. de Rooij A, van der Leeden M, Roorda LD, Steultjens MP, Dekker J. Predictors of outcome of multidisciplinary treatment in chronic widespread pain: an observational study. BMC Musculoskelet Disord. 2013;14(1):133.

13. Åkerblom S, Perrin S, Rivano Fischer M, Mccracken LM. The mediating role of acceptance in multidisciplinary cognitive-behavioral therapy for chronic pain. J Pain. 2015;16(7):606-615.

14. Sullivan MJ, Thorn B, Haythornthwaite JA, et al. Theoretical perspectives on the relation between catastrophizing and pain. Clin J Pain. 2001;17(1):52-64.

15. Mccracken LM. Learning to live with the pain: acceptance of pain predicts adjustment in persons with chronic pain. Pain. 1998;74(1):21-27.

16. Mccracken LM, Eccleston C. A comparison of the relative utility of coping and acceptance-based measures in a sample of chronic pain sufferers. Eur J Pain. 2006;10(1):23-23.

17. Keefe FJ, Rumble ME, Scipio CD, Giordano LA, Perri LM. Psychological aspects of persistent pain: current state of the science. J Pain. 2004;5(4):195-211.

18. Samwel HJ, Kraaimaat FW, Crul BJ, van Dongen RD, Evers AW. Multidisciplinary allocation of chronic pain treatment: effects and cognitive-behavioural predictors of outcome. Br J Health Psychol. 2009; 14(Pt 3):405-421.

19. Tay TG, Willcocks AL, Chen JF, Jastrzab G, Khor KE. A descriptive longitudinal study of chronic pain outcomes and gender differences in a multidisciplinary pain management centre. Pain Stud Treat. 2014;2(2):56.

20. Boonstra AM, Reneman MF, Waaksma BR, Schiphorst Preuper HR, Stewart RE. Predictors of multidisciplinary treatment outcome in patients with chronic musculoskeletal pain. Disabil Rehabil. 2015;37(14):1242-1250.

21. van der Hulst M, Vollenbroek-Hutten MM, Ijzerman MJ. A systematic review of sociodemographic, physical, and psychological predictors of multidisciplinary rehabilitation-or, back school treatment outcome in patients with chronic low back pain. Spine. 2005;30(7):813-825.

22. Gatchel RJ. Comorbidity of chronic pain and mental health disorders: the biopsychosocial perspective. Am Psychol. 2004;59(8):795-805.

23. Lame IE. Psychological predictors and treatment outcome in chronic pain. Cornell Family Papers. 2008.

24. Michaelson P, Sjölander P, Johansson H. Factors predicting pain reduction in chronic back and neck pain after multimodal treatment. Clin $J$ Pain. 2004;20(6):447-454.

25. Doménech J, Sanchis-Alfonso V, Espejo B. Changes in catastrophizing and kinesiophobia are predictive of changes in disability and pain after treatment in patients with anterior knee pain. Knee surgery, sports traumatology. Arthroscopy. 2014;22(10):2295-2300.

26. Farin E. The reciprocal effect of pain catastrophizing and satisfaction with participation in the multidisciplinary treatment of patients with chronic back pain. Health Qual Life Outcomes. 2015;13(1):163.
27. Baranoff J, Hanrahan SJ, Kapur D, Connor JP. Acceptance as a process variable in relation to catastrophizing in multidisciplinary pain treatment. Eur J Pain. 2013;17(1):101-110.

28. International Association for the Study of Pain. Epidemiology of neuropathic pain: how common is neuropathic pain, and what is its impact? 2014. Available from: https://s3.amazonaws.com/rdcmsiasp/ files/production/public/AM/Images/GYAP/Epidemiology $\% 20 \mathrm{of} \% 20$ Neuropathic\%20Pain.pdf. Accessed February 28, 2018.

29. Daniel HC, Narewska J, Serpell M, Hoggart B, Johnson R, Rice AS. Comparison of psychological and physical function in neuropathic pain and nociceptive pain: implications for cognitive behavioral pain management programs. Eur J Pain. 2008;12(6):731-741.

30. Finnerup NB, Haroutounian S, Kamerman P, et al. Neuropathic pain: an updated grading system for research and clinical practice. Pain. 2016;157(8):1599.

31. Schmidt-Ott R, Schutter U, Simon J, et al. Incidence and costs of herpes zoster and postherpetic neuralgia in German adults aged $\geq 50$ years: a prospective study. J Infect. 2018;76(5):475-482.

32. Johnson RW, Rice ASC. Postherpetic neuralgia. N Engl J Med Overseas Ed. 2014;371(16):1526-1533.

33. Harden RN, Bruehl SP. Diagnosis of complex regional pain syndrome: signs, symptoms, and new empirically derived diagnostic criteria. Clin J Pain. 2006;22(5):415-419.

34. England JD, Gronseth GS, Franklin G, et al. Distal symmetric polyneuropathy: a definition for clinical research: report of the American Academy of Neurology, the American Association of Electrodiagnostic Medicine, and the American Academy of Physical Medicine and Rehabilitation. Neurology. 2005;64(2):199-207.

35. Cruccu G, Finnerup NB, Jensen TS, et al. Trigeminal neuralgia: new classification and diagnostic grading for practice and research. Neurology. 2016;87(2):10-212.

36. Baron R, Maier C, Attal N, et al. Peripheral neuropathic pain: a mechanism-related organizing principle based on sensory profiles. Pain. 2017;158(2):261.

37. Williamson A, Hoggart B. Pain: a review of three commonly used pain rating scales. J Clin Nurs. 2005;14(7):798-804.

38. Pollard CA. Preliminary validity study of the pain disability index. Percept Mot Skills. 1984;59(3):974-981.

39. Dillmann U, Nilges P, Saile H, Gerbershagen HU. Assessing disability in chronic pain patients. Schmerz. 1994;8(2):100-110.

40. Fairbank JC, Couper J, Davies JB, O'Brien JP. The Oswestry low back pain disability questionnaire. Physiotherapy. 1980;66(8):271-273.

41. Gerbershagen HU, Lindena G, Korb J, Kramer S. Health-related quality of life in patients with chronic pain. Schmerz. 2002;16(4):271-284.

42. Pfingsten M, Schöps P, Wille T, Terp L, Hildebrandt J. Classification of chronic pain. Quantification and grading with the Mainz Pain Staging System. Schmerz. 2000;14(1):10-17.

43. Radloff LS. The CES-D scale: a self-report depression scale for research in the general population. Appl Psychol Meas. 1977;1:385-401.

44. Hautzinger M, Bailer M. [General depression scale]. Allgemeine Depressionsskala. 1. Auflage. Göttingen: Beltz Test GmbH; 1993. German.

45. Meyer K, Sprott H, Mannion AF. Cross-cultural adaptation, reliability, and validity of the German version of the Pain Catastrophizing Scale. J Psychosom Res. 2008;64(5):469-478.

46. Sullivan MJL, Bishop SR, Pivik J. The pain catastrophizing scale: development and validation. Psychol Assess. 1995;7(4):524-532.

47. Nilges $P$, Köster B, Schmidt CO. [Pain acceptance - concept and validation of a German version of the Chronic Pain Acceptance Questionnaire]. Schmerzakzeptanz-Konzept und Überprüfung einer deutschen Fassung des Chronic Pain Acceptance Questionnaire. Schmerz. 2007;21:57-67. German.

48. Myers R. Classical and Modern Regression with Applications. 2nd ed. Boston, MA: Duxbury; 1990.

49. Dworkin RH, Turk DC, Mcdermott MP, et al. Interpreting the clinical importance of group differences in chronic pain clinical trials: IMMPACT recommendations. Pain. 2009;146(3):238-244. 
50. Farrar JT, Young JP Jr, Lamoreaux L, Werth JL, Poole RM. Clinical importance of changes in chronic pain intensity measured on an 11-point numerical pain rating scale. Pain. 2001;94(2):149-158.

51. Torrance N, Ferguson JA, Afolabi E, et al. Neuropathic pain in the community: more under-treated than refractory? Pain. 2013;154(5):690-699.

52. Jensen MP, Turner JA, Romano JM. Changes after multidisciplinary pain treatment in patient pain beliefs and coping are associated with concurrent changes in patient functioning. Pain. 2007;131(1-2):38-47.

53. Turk, DC. A cognitive-behavioral perspective on treatment of chronic pain patients. In: Turk DC, Gatchel, RJ, editors. Psychological Approaches to Pain Management: A Practitioner's Handbook. New York: Guilford Press; 2002:138-158.

54. Geisser DS. A comparison of acceptance-focused and control-focused psychological treatments in a chronic pain treatment center [Unpublished doctoral dissertation]. Reno, NV: University of Nevada. 1992.

55. Viane I, Crombez G, Eccleston C, Devulder J, de Corte W. Acceptance of the unpleasant reality of chronic pain: effects upon attention to pain and engagement with daily activities. Pain. 2004;112(3):282-288.

56. Mccracken LM, Vowles KE. Acceptance and commitment therapy and mindfulness for chronic pain: model, process, and progress. Am Psychol. 2014;69(2):178-187.
57. Mccracken LM, Gutiérrez-Martínez O. Processes of change in psychological flexibility in an interdisciplinary group-based treatment for chronic pain based on acceptance and commitment therapy. Behav Res Ther. 2011;49(4):267-274.

58. Mccracken LM, Vowles KE, Eccleston C. Acceptance of chronic pain: component analysis and a revised assessment method. Pain. 2004;107(1-2):159-166.

59. Jensen MP, Turner JA, Romano JM. Changes in beliefs, catastrophizing, and coping are associated with improvement in multidisciplinary pain treatment. J Consult Clin Psychol. 2001;69(4):655-662.

60. Gracely RH, Geisser ME, Giesecke T, et al. Pain catastrophizing and neural responses to pain among persons with fibromyalgia. Brain. 2004;127(Pt 4):835-843.

61. Glombiewski JA, Hartwich-Tersek J, Rief W. Depression in chronic back pain patients: prediction of pain intensity and pain disability in cognitive-behavioral treatment. Psychosomatics. 2010;51(2): $130-136$.

62. Shaygan M, Böger A, Kröner-Herwig B. Neuropathic sensory symptoms: association with pain and psychological factors. Neuropsychiatr Dis Treat. 2014;10:897.

\section{Journal of Pain Research}

\section{Publish your work in this journal}

The Journal of Pain Research is an international, peer reviewed, open access, online journal that welcomes laboratory and clinical findings in the fields of pain research and the prevention and management of pain. Original research, reviews, symposium reports, hypothesis formation and commentaries are all considered for publication.

\section{Dovepress}

The manuscript management system is completely online and includes a very quick and fair peer-review system, which is all easy to use. Visit http://www.dovepress.com/testimonials.php to read real quotes from published authors. 